WOJCIECH SITEK

Instytut Dziennikarstwa i Komunikacji Społecznej

Uniwersytet Wrocławski

\title{
Kolor pieniędzy. Filmowy styl Michaela Manna
}

\begin{abstract}
AвSTRACT. Sitek Wojciech, Kolor pieniędzy. Filmowy styl Michaela Manna [The color of money. Michael Mann’s film style]. "Images” vol. XXVII, no. 36. Poznań 2020. Adam Mickiewicz University Press. Pp. 197-214. ISSN 1731-450X. DOI 10.14746/i.2020.36.13.

According to film studies experts, Michael Mann's movies has the look and the smell of reality. The polisensoric character of his works is used to exhibit the aura of non-screen reality. Michael Mann uses narrative and stylistic elements to show the destructive side of social inequalities. In his genre films, he is presenting themes of social injustice and toxic corporate system (which are often hidden behind the elegant façade of late capitalism's aesthetics).
\end{abstract}

KeYwords: Michael Mann, aesthetics of late capitalism, Thief, Manhunter, Heat, The Insider, Ali, Collateral, Miami Vice

W scenie otwierającej film Informator (1999) Lowell Bergman, producent uznanego programu publicystycznego, kieruje się na spotkanie z liderem organizacji Hezbollah. Mężczyzna przemierza drogę na tylnym siedzeniu samochodu. Spod płóciennej opaski zakrywającej twarz nie dostrzega nawet zarysu mijanych lokacji. Choć odbiorca, w przeciwieństwie do Bergmana, widzi ulice libańskiego miasta, to pozostaje równie zdezorientowany jak bohater. Dynamiczne ruchy kamery i nieostre ujęcia, absurdalne zbliżenia, które utrudniają rozpoznanie przedmiotów, chaotyczne przejścia od detalu do szerokiego kadru i z powrotem czy wreszcie nieumotywowane „wejścia” obiektywu wprost w sylwetki przechodniów, nie konstytuują klarownego obrazu świata. Szereg krótkich spojrzeń - na twarz dziecka, lufę karabinu, linie wysokiego napięcia, rozrośnięte palmowce - stanowi zaproszenie do świata ciągłej zmiany, którego nie sposób ująć w ramy zorganizowanej i uporządkowanej całości.

W tej gorączkowo nakręconej sekwencji ważniejsze niż oblicza i fasady są wszystkie inne własności mijanych ludzi, przedmiotów i miejsc. Ekranowa rzeczywistość Michaela Manna rozrasta się w wielu wymiarach. Do uszu bohatera co rusz dobiegają przeraźliwe, szybko urywające się dźwięki, którym Bergman nie potrafi przypisać źródła. Atmosfera bliskowschodniego „kotła” jest uzupełniana niemalże wyczuwalnymi zapachami dymu papierosowego i ulicznego jedzenia. Nagłe skręty i zmiany prędkości pojazdu powodują drżenie foteli. Pył i uliczny brud osadzają się na ciele producenta. Percypując rzeczywistość wieloma zmysłami, protagonista nie musi więc widzieć, by poznawać okalający go świat. Mimo że adresat filmu może kierować się wzro-
Images

vol. XXVII/no. 36

Poznań 2020

ISSN 1731-450X 
kiem w odbiorze pozawzrokowych doznań, to z przywołanej sekwencji da się wydobyć coś więcej niż jedynie wizualizację pejzażu Baalbek. Uchwycenie całościowej tonacji wyprawy na Bliski Wschód wymaga zaprzęgnięcia do współpracy kilku zmysłów. Nastrój odwiedzanych miejsc oraz aura towarzyszących im wydarzeń są możliwe do poznania jedynie przy akceptacji polisensorycznego charakteru twórczości Manna. Choć reżyser uchodzi za ekranowego stylistę[1], który uprzywilejowuje wrażenia wzrokowe, to doznawanie ,jego" świata polega na aktywnym odczytywaniu śladów o różnej proweniencji, słowem: odbiór wymaga oddania się zmysłowej synestezji. Zalecenie jednoczesnego chłonięcia wielu sygnałów charakteryzuje profil „kina totalnego”[2] Manna - kina, jak zauważa Artur Piskorz, „mającego wygląd, smak i zapach rzeczywistości”[3].

Podobną scenę Mann zaaranżuje później w filmie Ali (2001). Przebieżka tytułowego bohatera, do której dołączają dziesiątki Zairczyków, z początku uchyla panoramę kinszaskich slumsów, jednak z czasem okazuje się oznaką emocjonalnej wspólnoty pariasów. W kraju, w którym dyktator Mobutu, chwilowy sprzymierzeniec Międzynarodowego Funduszu Walutowego i Banku Światowego, kieruje się dewizą, że „Wszystko jest na sprzedaż i wszystko można kupić”[4], to właśnie w więzi wykluczonych tli się nadzieja: naznaczona potem, brudem i głodem, manifestująca się w muralach, śpiewach i fizycznej bliskości. Kiedy Ali na moment staje się członkiem tej wspólnoty, kadry sycą się barwami, ruch kamery spowalnia, a w tle rozbrzmiewają melancholijne dźwięki utworu malijskiego muzyka Salifa Keïty - wtedy odsłania się subiektywna prawda o rzeczywistości. Reżyser sięga po ślady codzienności, by poprzez nie opowiadać o życiu jednostek w realiach drugiej połowy XX wieku. Unaocznione w technice realizacyjnej Zakładnika (2005) przywiązanie do kamery cyfrowej, którą Mann uznał za lekarstwo na swoje chorobliwe pragnienie uchwycenia głębi pejzażu (zwłaszcza nocnego), uświadamia, że twórcę interesuje przede wszystkim precyzyjny ogląd przestrzeni życiowej[5]. Analiza poszczególnych przejawów świata uwikłanego w ideologię późnego kapitalizmu pozwala mu na odzwierciedlenie aury współczesności, kompleksowo oddziałującej na funkcjonujących w niej ludzi.

[1] Mann od kilkudziesięciu lat zwraca uwagę na uproszczony charakter tej obserwacji. Mówi przekornie: „Styl to nieprzyzwoite słowo”. D. Haithman, This man's got a 'vice' he can live with: 'style is a dirty word,' Producer Michael Mann says, „Los Angeles Times” 1987, 17. November, <https://www.latimes.com/archives/la-xpm-1987-11-17-ca-22158-story.html>, dostęp: 10.03.2020.

[2] Zob. A. Piskorz, Michael Mann - antropolog doświadczenia, [w:] Mistrzowie kina amerykańskiego. Współczesność, red. Ł.A. Plesnar, R. Syska, Kraków 2010, s. 185.

[3] Ibidem, s. 208.
[4] M. Davis, Planeta slumsów, przeł. K. Bielińska, Warszawa 2009, s. 264.

[5] Mann zwraca przy okazji uwagę na swoją przynależność do technicznej awangardy. Reżyser porównuje afirmację kamery cyfrowej do pochwały tak zwanej estetyki stalowej struktury, której dokonali chicagowscy architekci u schyłku XIX wieku, wyłamujący się trendowi do ukrywania stali pod kamiennymi fasadami. Zob. M. Mann, Paint it Black, rozm. przepr. M. Olsen, [w:] Michael Mann. Cinema and Television. Interviews, 1980-2012, red. S. Sanders, R.B. Palmer, Edinburgh 2014, s. 81. 
Zwieńczenie epizodu w Baalbek w mniej zawoalowany sposób Witaj w świecie! tłumaczy artystyczne stanowisko Manna. Tuż po rozmowie z szejkiem Fadlallahem bohater Informatora w końcu zdejmuje opaskę i rozgląda się wokół siebie, by momentalnie potwierdzić koherencję wszystkich wcześniejszych doznań. Rozsuwa okienne zasłony niczym kotary w kinoteatrze i teraz już wzrokowo odbiera sygnały, które docierały do niego podczas podróży samochodem. Widzi rażące światło, ruch uliczny, źródła zapachów i miejski brud. Odczuwane przedtem bodźce zyskują naoczne potwierdzenie. Bohater może wreszcie wykrzyknąć: „Witaj w świecie!”, stając się przy okazji symbolicznym medium reżysera. Ze wskazanej deklaracji wyłania się Mannowska etyka pracy, ukierunkowana na drobiazgowe prezentowanie wyimków nieostrej i wieloaspektowej, często nieokreślonej i trudnej do uchwycenia rzeczywistości.

Oznaczanie Manna etykietą wizualnego stylisty, choć uprawnione, nie jest w pełni zasadne - oddaje bowiem jedynie część jego strategii autorskiej. Sygnaturę twórcy wyznacza splot przypadkowych doznań, bogactwo fizykalnych wrażeń i spiętrzenie afektów. Todd McGowan rozważa nawet orientację reżysera w kontekście nadmiaru, który charakteryzuje nie tylko poczynania filmowych bohaterów, ale też fanatyczne poświęcenie pracy i momentami patologiczny[6] perfekcjonizm reżysera[7]. Istotnym elementem owej „etyki nadmiaru” jest nadwyżka zmysłowych doznań. Sprawia ona, że proces doświadczania filmu nie uprzywilejowuje wizualności samej w sobie, lecz polega na skorelowaniu jej ze wskazówkami pozawzrokowymi. Korzystając z wykładni Jennifer Barker, można dookreślić nadmiar jako jakość faworyzującą percepcję synestetyczną. Poprzez przekroczenie ram jednozmysłowej modalności oraz unieważnienie podziałów i hierarchii, przypominanych czasem w ramach refleksji na temat „zmysłowości” kina[8], Mann kształtuje spektakl oddający nastrój czasów późnego kapitalizmu. W kontekście uprawianego przez autora Goraczki (1995) modelu kina, wymagającego od widza skojarzeń intermodalnych, należałoby więc dokonać niewielkiego przesunięcia w zakresie przedmiotu badań. Liczba teoretycznych rozpoznań „estetyki” reżysera (aesthetics) uzmysławia niedostateczne zainteresowanie „synestetyzmem” jego twórczości (synaesthetics). Być może tuż obok kluczowego pojęcia „stylu” powinien zatem lokować się termin filmowej „aury”, okalającej światy ukazane w dziełach Michaela Manna.

[6] Jay Holben zwraca uwagę na konflikt Manna $\mathrm{z}$ operatorem Paulem Cameronem oraz fakt zaistnienia „różnic artystycznych” podczas prac nad $\mathrm{Za}$ kładnikiem. Zob. J. Holben, Hell on wheels: Collateral, "American Cinematographer" 2019, 18, October, $<$ https://ascmag.com/articles/hell-on-wheels-collateral>, dostęp: 10.03.2020. Matt Zoller Seitz przywołuje $\mathrm{z}$ kolei epizod z planu Informatora. Ponoć jedna ze scen musiała zostać nagrana ponownie, bo Mannowi nie podobał się kolor krawata jednego z bohaterów.
Zob. M.Z. Seitz, Zen Pulp, „Moving Image Source” 2009, <http://www.movingimagesource.us/articles/ zen-pulp-pt-1-20090701>, dostęp: 10.03.2020.

[7] Zob. T. McGowan, Realne spojrzenie. Teoria filmu po Lacanie, przeł. K. Mikurda, Warszawa 2008, s. 85-91.

[8] Por. J.M. Barker, Out of sync, out of sight: Synaesthesia and film spectacle, „Paragraph” 2008, nr 31, s. 237. 
W dobie utowarowienia kultury i prymatu informacji cyfrowej styl Manna sygnalizuje „walkę o powrót realnego, protest przeciw coraz bardziej globalnym spektaklom symulacji”[9]. Aura, częściowo wywiedziona $\mathrm{z}$ wykładni Waltera Benjamina, wbrew zapowiedziom niemieckiego filozofa przetrwała reprodukcję techniczną. Jak zauważa Paweł Mościcki, można ją dziś traktować jako „rodzaj dodatku, czy też naddatku, w obrazie, który jednocześnie decyduje o jego wyjątkowości, jego specyficznym i niepowtarzalnym błysku”, który „pojawia się wraz z obrazem, nawiedza go, ale zarazem nie daje się do niego zredukować" [10]. Mann korzysta z owego mgnienia w sposób szczególny. Jego autorski wariant aury wynika najprawdopodobniej z potrzeby ujawnienia wielozmysłowej relacji, zachodzącej między osamotnionymi bohaterami i przytłaczającym ich światem. Mościcki w dalszej części rozważań zwraca uwagę na sedno myśli Benjamina. $Z$ jednej strony, jak w zwyczajowym odczytaniu, sygnalizuje zanik aury, powodowany masowością technicznej reprodukcji, a z drugiej koncentruje się na wywrotowym charakterze tego procesu. Uśmiercenie aury może prowadzić do otwarcia się na nową auratyczność, odzwierciedlającą dynamikę nowoczesności[11]. W tym polu sytuuje się twórczość Michaela Manna - autora snującego elegijne opowieści o upadającym świecie.

Ku zmysłowej synestezji
Realia Stanów Zjednoczonych schyłku XX wieku są przez Manna prezentowane dwojako. Zarówno z niezaangażowanego punktu widzenia, jak i spersonalizowanego - tłumaczącego, w jaki sposób bohaterowie reagują na rzeczywistość i jak ta na nich oddziałuje. Świadomość, że podstawowym problemem społecznym w Zakładniku są nierówności ekonomiczne, nie wynika jedynie $\mathrm{z}$ wizualnego rozdźwięku między postaciami taksówkarza i elitarnego mordercy. Decydująca jest aura towarzysząca Maksowi - sprekaryzowanemu kierowcy, którego wstyd, niepewność i zakłopotanie z czasem udzielają się widzowi. Choć od wielu lat mężczyzna ciężko pracuje, to biznesowy plan założenia własnej firmy ciągle pozostaje nieziszczalny. Zdaniem Scotta Foundasa wszystko, co stanowi o mise-en-scène utworów Manna, wyrasta z bohaterów i jest formą ekspresji ich stanów wewnętrznych[12]. Kiedy po destrukcyjnych spotkaniach z rzekomymi „ludźmi sukcesu” bohater dochodzi do psychicznej równowagi, kamera drobiazgowo analizuje jego postać. Obiektyw sytuuje się wtedy blisko protagonisty: wnika w jego przestrzeń osobistą, a w efekcie twarz Maksa, skąpana w zielono-żółtej poświacie, traci ostre kształty. Świat wokół bohatera symbolicznie się pomniejsza. Słychać wtedy jedynie westchnienia taksówkarza, który, mimo porażek, ciągle snuje niemożliwe do zrealizowania marzenie o sukcesie. Wiedza odbiorcy na temat sytuacji postaci jest wsparta
[9] Zob. L. Koepnick, Aura widziana na nowo. Benjamin i współczesna kultura wizualna, przeł. K. Kosińska, „Kwartalnik Filmowy” 2008, nr 64, s. 38.

[10] P. Mościcki, Odrodzenie aury z ducha fotogenii, „Teksty Drugie” 2016, nr 2, s. 90.
[11] Ibidem, s. 96.

[12] Zob. S. Foundas, A Mann's man's world, „LA Weekly” 2006, 26 lipca, <https://www.laweekly. com/news/a-manns-mans-world-2144449>, dostęp: 10.08.2019. 
z jednej strony na „przezroczystej” obserwacji realiów, a z drugiej na zbliżaniu się do Maksa i współodczuwaniu z nim. Świat późnego kapitalizmu, obdarzany spojrzeniem $z$ dystansu, ujawnia swoją aurę dopiero $\mathrm{w}$ chwilach, kiedy protagoniści mierzą się z poszczególnymi jego problemami.

Jeśli odbiór rzeczywistości wszystkimi zmysłami można uchwycić w ramy audiowizualnego manifestu, to ten najdosłowniej został wyrażony w Czerwonym smoku (1986), filmie relacjonującym zmagania detektywa Willa Grahama z seryjnym mordercą Francisem Dollarhydem. Ci bohaterowie wydają się szczególnie wyczuleni na aurę rzeczywistości. Odbierając świat pełniej niż inne postacie, reagują dyskomfortem na biurową duchotę, nienaturalną pustkę ulic czy nieprzyjemną jaskrawość poranka. Z powodu dotkliwego osamotnienia percepcyjnego obaj szukają możliwości wyrażenia potrzeb zmysłowych. Współpracujący z FBI konsultant wykorzystuje swoje synestetyczne zdolności do zanurzania się w jaźnie przestępców. Jego rywal zaspokaja skłonności, aranżując wyszukane spektakle zbrodni. Morderca, nazywany przez dziennikarzy Zębową Wróżką, organizuje scenerię na wzór przestrzeni katoptrycznej, w której staje się nie tylko odtwórcą głównej roli, ale także widzem, obserwującym własne poczynania w refleksach luster umieszczonych w oczach ofiar. W kontekście tej perwersji widzialności interesująca jest strategia reżyserska Manna, który nie eksponuje aktów przemocy. Ich przebieg relacjonuje poprzez pracę policyjnego profilera, dysponującego jedynie rejestracjami z miejsc zbrodni.

W filmie dokonuje się także odsłonięcie mniej zdegenerowanych potrzeb psychopatycznego mordercy. Dollarhyde zaprasza na spotkanie towarzyskie niewidomą koleżankę z pracy, która - ze względu na doświadczenie niepełnosprawności - miałaby „widzieć więcej”. Kiedy w trakcie zaaranżowanej wizyty u weterynarza kobieta dotyka gęstego futra tygrysa, przykłada dłoń do otwartej paszczy zwierzęcia, chłonie jego ciepło i nasłuchuje bicia serca, Dollarhyde wchodzi w stan niemal ekstatyczny. W tym momencie diegetyczna opowieść o sile doświadczeń pozawzrokowych przenosi się na poziom realizacyjny. Styl można tu traktować - podobnie jak pisał Michael Riffaterre w odniesieniu do krytyki literackiej - jako „uwydatnienie”, ponieważ „język wyraża, a styl podkreśla”[13]. Wnętrze gabinetu weterynaryjnego skąpane jest w bieli, niczym sypialnie, w których Dollarhyde realizuje swoje perwersyjne pragnienia. Rozchwiane spojrzenie kamery pozwala dostrzec peryferie kadru, a rozmyte krawędzie nadają nieostrym zdjęciom melancholijnej tonacji[14]. Powolne tempo tej zmysłowej, seksualnej fantazji jest wyznaczane przez hipnotyczne dźwięki utworu Coelocanth grupy Shriekback. W późniejszej sekwencji, będącej rewersem przywołanego epizodu, Dollarhyde ponawia sytuację synestetyczną. Tuż po stosunku

[13] M. Riffaterre, Kryteria analizy stylu, „Pamiętnik Literacki” 1972, nr LXIII z 3, s. 221.
[14] Zob. R.W. Knight, Michael Mann's Miami Vice, „Reverse Shot” 2008, 26. April, <http://www.reverseshot.org/symposiums/entry/70/michael_mann>, dostęp: 20.02.2020. 
seksualnym zaczyna „chłonąć” swoją partnerkę: nie tylko ją ogląda, ale też wącha, dotyka i nasłuchuje bicia jej serca, a w końcu przenosi dłoń kobiety wprost w swoją „paszczę”.

Richard Brody zwrócił uwagę, że Mann jest stylistą w konkretnym znaczeniu - jego styl nie jest sednem historii, lecz uzupełnieniem treści[15]. Reżyser zachowuje równowagę poszczególnych aspektów filmu. Rys dramatyczny utworu, napięcie, nastrojowość, muzyczne wyczucie, rytm, decyzje estetyczne, konstrukcja scenariusza i tempo akcji fundują, zdaniem Brody'ego, zbalansowaną całość. Steven Rybin używa frazy „wydarzenie stylistyczne”, by omówić te elementy realizacyjne, które wydobywają ze świata przedstawionego niuanse rzeczywistości[16]. Pochodzą one $z$ wnętrza historii i mają swoje fabularne uzasadnienie, nie będąc przy tym uniwersalnym, spajającym całą filmografię reżysera, wehikułem narracji. Ostatecznie, strategia Manna ulega ciągłym - często krytykowanym - przekształceniom. Kojarzone z jego pierwszymi, „połyskliwymi” filmami (wyraźnie inspirowanymi estetyką noir) kadry neonowych miast i zdjęcia z mieniących się lustrzanymi odbiciami miejsc zbrodni ustąpiły słonecznym plażom Miami, uchwyconym w poetyce wideoklipowej (Policjanci $z$ Miami, 1984-1990). Później pojawił się chłodny i rzeczowy Informator, w którym więcej uwagi niż pejzażom reżyser poświęcił błyskotliwym, dynamicznie zmontowanym scenom dialogowym. Coraz częstsze w XXI wieku sięganie po kamerę cyfrową także zmodyfikowało styl autora. Zamiast więc poszukiwać konsekwencji estetycznej, co - zdaniem Rybina - prowadziłoby w końcu do zaistnienia interpretacyjnego delirium oraz przekonania o ciągłym przybliżaniu się do i oddalaniu od stylistycznego monolitu[17], należałoby dostrzec konsekwencję w wyzyskiwaniu atmosfery rzeczywistości. Styl wizualny Manna komponuje się z weltanschauung[18], zespołem przekonań na temat przemian społeczno-politycznych Stanów Zjednoczonych.

Film

(nie)ideologiczny
W kinie amerykańskim schyłku XX wieku przypływ refleksji na temat realiów społecznych nie prowadził do wzmocnienia świadomości ideologicznej i prób przepracowania konfliktów klasowych. Powstał wówczas szereg filmów operujących ironią i dzieł autotematycznych, obnażających zasady oddziaływania medium, a przez to poniekąd „rozgrzeszających" ówczesny stan rzeczy. Obecne w tym szerokim spektrum Gra (1997) i Podziemny krag (1999) Davida Finchera, American Psycho (2000) Mary Harron, Świadek mimo woli (1984) Briana De Palmy, 9 pót tygodnia (1986) Adriana Lyne’a, Urodzeni mordercy (1994) Olivera Stone'a, Napad (1993) Rogera Avary'ego, proponowały wielopoziomowe
[15] Zob. R. Brody, The stylish, empty realism of Michael Mann, „The New Yorker” 2016, 5. February, $<$ https://www.newyorker.com/culture/richard-brody/ the-stylish-empty-realism-of-michael-mann>, dostęp: 16.03.2020.
[16] Zob. S. Rybin, Michael Mann. Crime Auteur, Lanham 2013, s. 81.

[17] Ibidem, s. xxxiii.

[18] Zob. A. Helman, Refleksje teoretyczne. Kilka uwag o stylu w filmie, „Kino” 1978, nr 4, s. 35. 
i skomplikowane opowieści, w których kolejne piętra narracji sugerowały poruszanie się w obrębie nierzeczywistej rzeczywistości.

W odróżnieniu od części filmów z przełomu wieków, których autorzy uprawiali krytykę ideologiczną z wykorzystaniem narzędzi postmodernistycznych, realizacje Manna nie opierają się na „podwójnym widzeniu”[19]. Podejmując problematykę współczesną, reżyser generuje przekaz względnie przezroczysty w planie ideologicznym i światopoglądowym. Zagłębia się co prawda w świecie wzbudzającym jego wątpliwości moralne i wykłada szereg problemów cywilizacyjnych: wyniszczające przywiązanie do pracy, rozkład stabilności życiowej, rozpad stosunków międzyludzkich, ekonomię późnego kapitalizmu czy ponowoczesną inwigilację. Choć wszystkie te aberracje mają zaczątek w praktyce neoliberalnej ideologii, to Mann nie dokonuje apriorycznej krytyki systemu. Trzyma się blisko swoich bohaterów i stopniowo rozpoznaje rzeczywistość od wewnątrz, stroniąc od roli nadzorcy z odizolowanego, zewnętrznego punktu widokowego.

Jak zauważa Knight, to, co współcześnie jest traktowane jako znajome i dobrze rozpoznane, w twórczości Manna nabiera niepokojącego charakteru obcości. Z kolei to, co w realiach pozafilmowych zwykle tkwi na percepcyjnych peryferiach, w filmach skupia szczególną uwagę[20]. Zamiast oswajać ponowoczesny świat, reżyser zachowuje względem niego dystans. Przyjmuje punktowy sposób oglądu, który pozwala mu wyławiać problemy istotne z perspektywy jednostki. Manifestując złowrogie oddalenie rzeczywistości i jej widmową naturę, twórca ignoruje środki wypracowane przez autorów filmów progresywnych narracyjnie - te mogłyby przecież omglić specyfikę ideologii i ukryć najdotkliwsze jej wady. Uwzględniwszy szeroką gamę środków przedstawiania, Mann rzadko sięga po te, które tworzyłyby dodatkowy system odniesienia. Symptomatyczny wydaje się casus serialu Policjanci $z$ Miami - posępnego z początku, który w późniejszych sezonach, kiedy producencki nadzór Manna był słabszy, stał się nośnikiem żartu i kpiny. Wyważony ton, jakim posługiwali się twórcy serialu i wygłaszane w początkowych odcinkach sądy, dotyczące konfliktu w Nikaragui i postępującej polaryzacji społecznej, ustąpiły miejsca autoironicznym, farsowym elementom.

Gdyby pokusić się o stworzenie w kinie przełomu wieków podziału na „reżyserów, którzy wierzą w rzeczywistość” i „reżyserów, którzy (wzorem postmodernistów) wierzą w nierzeczywistość", wielozmysłowy świat Michaela Manna wyróżniałby się jako ten, który „śmierdzi kapustą”[21]. W odróżnieniu od twórczości naturalistów, w filmach amerykańskiego reżysera nutą zapachową "kapusty” jest kapitalizm i pozorna sytość, a nie bieda i głód. Źródłem krzywdy naj-

[19] C. Sharrett, Michael Mann. Elegies on the post-industrial landscape, [w:] Fifty Contemporary Filmmakers, red. Y. Tasker, Routledge, London, New York 2002, s. 254.
[20] Zob. R.W. Knight, op.cit.

[21] F. Jameson, Postmodernizm, czyli logika kulturowa późnego kapitalizmu, przeł. M. Płaza, Kraków 2011, s. 286. 
częściej jest bowiem „szczęście, a przynajmniej zadowolenie (które jest w rzeczywistości samozadowoleniem), «fałszywe» szczęście Marcusego [...] - pod tą właśnie błogością kryje się niedola, nieszczęście, które nie ma nazwy, które nawet nie wie, że różni się od autentycznej satysfakcji i spełnienia" [22].

Wysokobudżetowe filmy i seriale Manna są ewidentnie uwikłane ideologicznie (jak większość hollywoodzkich realizacji zaprzęgniętych w system produkcji i dystrybucji), jednak wykazują przy okazji krytyczną orientację. Fetyszyzacja neoliberalnych idei przez bohaterów sprzyja subwersywnemu obnażeniu martwoty i zgnilizny systemu. Jeśli przyjąć wykładnię Louisa Althussera, który wskazywał, że ideologia narzuca „oczywistości jako oczywistości, że nie możemy ich nie rozpoznać i wobec których nieuniknioną i naturalną reakcją jest krzyknąć (pełnym głosem lub w „ «zaciszu świadomości»): «To oczywiste. Tak jest. To prawda!»"[23], to u Manna oczywistości jawią się jako sporne i budzące wątpliwości. Nie dlatego, że twórca zjadliwie je punktuje, lecz dlatego, że utrzymuje wobec nich dystans: w tym wariancie krytyka dokonuje się z perspektywy poszczególnych bohaterów. Tropienie śladów amerykańskiej mitologii prowadzi reżysera do jednostek, które zostały skrzywdzone mrzonkami o sukcesie. Protagoniści ostatecznie poddają się upodmiotowieniu albo odpodmiotowieniu - a więc wchodzą w szpony późnego kapitalizmu lub się z nich wyrywają [24].

Jednym z najbardziej interesujących Manna tematów są korporacyjne rozgrywki, które we wszystkich filmach zyskują wyraźną manifestację wizualną. Począwszy od debiutanckiej Mili jerychońskiej (1979), w której gra kolorem komentuje konflikty klasowe i etniczne, przez Złodzieja (1981), odbijającego w lakierowanych powierzchniach złudzenia amerykańskiego snu, kończąc na Zakładniku, filmie operującym zielono-żółtymi barwami klaustrofobii, ogarniającej tytułowego bohatera, Mann konsekwentnie kroczy za bohaterami, mierzącymi się z drapieżną rzeczywistością. Protagoniści, kierowani wiarą w lepsze jutro, zanurzają się w postindustrialnym świecie zawiedzionych nadziei, chciwości, zepsucia i cynizmu. Aura w filmach Michaela Manna jest ufundowana na zderzeniu „obiektywnego” portretu świata, z uczuciem żywionym wobec bohaterów, którzy biorą udział w nierównej walce $\mathrm{z}$ dysponentami władzy symbolicznej.

W poszukiwaniu aury

Bohaterowie twórczości Manna sytuują się w podrzędnej pozycji wobec zleceniodawców. Stymulowani korporacyjną nowomową, intensyfikują poziom swojej mobilności przestrzennej, konsumpcji i ruchliwości pionowej. Wszystko po to, by znaleźć się na szczycie drabiny społecznej. Każdorazowo rozpada się ta iluzja nieograniczonych

[22] Tymi słowami Jameson charakteryzuje przekazy relacjonujące nastrój epoki Dwighta Eisenhowera. Ibidem.

[23] L. Althusser, Ideologie i aparaty ideologiczne państwa, przeł. A. Staroń, „Recykling Idei” 2006,
$<$ http://recyklingidei.pl/althusser-ideologie-aparaty-ideologiczne-panstwa>, dostęp: 16.03.2020.

[24] Zob. L. Koepnick, op.cit., s. 43. 
możliwości, a wtedy protagoniści orientują się, że utknęli w zatrutej przestrzeni. Żywiona wcześniej nadzieja na lepszą przyszłość ustępuje poczuciu braku sensu. W Informatorze główni bohaterowie obnażają nieetyczne praktyki branży zarządzanej przez big tobacco. Za chwilowy i wątpliwy w gruncie rzeczy sukces przychodzi im zapłacić wysoką cenę. W jednej z końcowych sekwencji filmu partnerka Begmana pociesza go: „Wygrałeś", jednak mężczyzna nie podziela jej entuzjazmu i dopowiada jedynie: „Tak, tylko co?”.

Protagoniści filmów Manna są nośnikami ideologii - ofiarami jej przemożnego i niezauważalnego wpływu. Choć na pozór reżyser gloryfikuje współczesność, to kształtowana przez niego atmosfera stanowi sugestywną wskazówkę, rozbijającą mrzonkę amerykańskiego snu. Gra kolorem, oświetlenie, kompozycja kadru, cielesne relacje między bohaterami i muzyka wyrażają odrazę do neoliberalnej rzeczywistości. Samotnych, przemieszczających się z miejsca na miejsce, poświęconych pracy i zorientowanych na bogacenie bohaterów otacza nastrój nieszczęścia, pustki i wiecznych zobowiązań. Aura w filmach Manna definiuje, właściwe społeczeństwu schyłku XX wieku, poczucie „Zagubienia, dezorientacji i konsternacji”, wynikające, jak pisze Zygmunt Bauman, z nieuchwytności (lub złudności) życiowych celów[25].

Tytułowy bohater Złodzieja, podejmując próbę realizacji awansu ekonomicznego, skazuje się na los wiecznego dłużnika. Wszystkie marzenia Frank pragnie bowiem realizować zgodnie z logiką późnego kapitalizmu - nawet rodzinę zakłada niczym działalność gospodarczą. Kiedy wniesione przez Franka i Jessie dokumenty adopcyjne zostają zakwestionowane ze względu na kryminalną przeszłość mężczyzny, bohater wypomina pracowniczce socjalnej mechanizmy przemocy instytucjonalnej, której sam doświadczył, będąc wychowankiem domu dziecka. Złodziej przypomina nie tylko o życiu w małym, zielonym pokoiku, ale też ostatecznym akcie kapitulacji w obliczu opresji: „Moje życie należy do was". W końcu, dzięki pomocy Leo, lidera organizacji mafijnej, partnerom udaje się nabyć dziecko. „Poród” odbywa się w hotelowym lobby. Z windy, rozświetlonej ostrzegawczą, jasnozieloną poświatą, wychodzi opiekunka i przekazuje noworodka Jessie. Chwilę później rodzice świętują narodziny chłopca w restauracji. Marzenie (albo zachcianka) pary zostaje spełnione, ale bohaterowie nie okazują szczególnej radości. W scenie zmontowanej w układzie ujęcie-przeciwujęcie nie widać nawet twarzy chłopca. Pozór szczęścia poświadcza wnętrze lokalu - młodych rodziców otaczają zielone ściany, a czerwone elementy wystroju fundują wokół nich labiryntową strukturę.

W kulminacyjnym momencie filmu Frank wysłuchuje tyrady swojego mocodawcy. Stojący nad pobitym mężczyzną gangster wykłada mu specyfikę relacji biznesowych. Kadrowany z żabiej perspektywy Leo informuje Złodzieja: „Twój dzieciak jest mój, ja go kupiłem. Ty tylko wypożyczyłeś, wynajmujesz go". Aura sekwencji, naznaczona

[25] Z. Bauman, Życie na przemiał, przeł. T. Kunz,

Kraków 2004, s. 30. 
jaskrawo-zielonym światłem jarzeniówek, znamionuje wszechobecne zagrożenie. Tuż po deklaracji przestępcy następuje jeszcze szereg nielogicznych cięć montażowych, oddających rozpad psychiczny Franka. Ujęcia są rwane, pozbawione płynności, a Leo kieruje się raz w prawą, a raz w lewą stronę kadru. Jeśli uznać, że czasem styl filmowy może zasłaniać profil portretowanych realiów, to w twórczości Manna aura wydobywa faktyczny ich kształt: skażony przemocą ekonomiczną i wątpliwymi praktykami korporacyjnymi, które ukrywa się za mirażami, wizerunkami profesjonalistów, przytłaczającą architekturą i barierą trudnych do zniesienia dźwięków.

\section{Aura późnego kapitalizmu}

[26] Zob. F.X. Feeney, Michael Mann, Los Angeles 2006, s. 62.
Choć Mann lokuje się w pewnym oddaleniu od twórców słynących $z$ wizualnego ekscentryzmu, to jednocześnie nie odżegnuje się od narzędzi kreacji, które pozwalałyby mu wyostrzać rzeczywistość. W Czerwonym smoku wyostrzenie wydarza się kilka razy. W sekwencji rozgrywającej się w szpitalu psychiatrycznym Will Graham doświadcza napadu paniki. Niepokój bohatera wzmaga się w celi Hannibala Lecktora, psychopatycznego mordercy zjadającego swoje ofiary. Spotkanie mężczyzn jest zaaranżowane na wzór sytuacji lustrzanej. Osią symetrii $\mathrm{w}$ tym niewielkim, niemal całkowicie białym pomieszczeniu są przebiegające wzdłuż pokoju kraty. Właściwą interakcję z Lecktorem poprzedza moment wyciszenia. Kamera jest oddalona od sylwetki Willa, a lokum wydaje się względnie przestronne. Kiedy jednak kanibal unosi się z łóżka i zajmuje pozycję naprzeciw detektywa, perspektywa się zmienia. Jak zauważa F.X. Feeney, obiektyw zbliża się do Grahama, prezentując zwiększoną aktywność zmysłową bohatera[26]. Klaustrofobiczne wnętrza postmodernistycznej budowli symbolicznie zacieśniają się wokół niego. Protagonista traci obiektywizm spojrzenia i zrywa się do ucieczki. Chwilę później wpatruje się w przyszpitalny trawnik. Zieleń klombów mieni się połyskliwymi refleksami, a barwa uznawana zwykle za kojącą, zaczyna przypominać truciznę Scheelego. Kiedy mężczyzna rozluźnia krawat (tym samym także swoje zobowiązania), kolory otoczenia wracają do „normy”.

Podpatrywanie świata ma w filmach Manna obiektywny zaczątek, jednak spojrzenia poszczególnych bohaterów przydają mu subiektywnego charakteru. Połączenie obu tych modeli reprezentacji w pełni oddaje aurę przełomu wieków. Ekranowe realia okazują się rozszczepione przez świadomość bywalców ponowoczesnego świata. Autor Złodzieja wciąż ponawia zresztą zaproszenie do Bazinowskiego „kina totalnego". Gorączkowa rzeczywistość zyskuje w jego filmach kształt polifonicznego widowiska, w którym do głosu dochodzą postacie co dzień mierzące się z niepewnością.

Jak zauważa Nick Srnicek, złożoność i abstrakcyjność globalnych rynków wymaga równie złożonych i abstrakcyjnych form estetycznej reprezentacji[27]. W filmach Manna rolę tę odgrywa poetyka, którą Ar-
[27] Zob. N. Srnicek, Navigating Neoliberalism. Political Aesthetics in an Age of Crisis, <https://vimeo. com/52434614>, dostęp: 24.02.2020. 
tur Piskorz ujmuje w ramy tak zwanego kina doświadczenia - modelu realizacyjnego polegającego na przedstawianiu rzeczywistości „przefiltrowanej przez psychikę bohatera" [28]. Reżyser nie tworzy całościowej rekonstrukcji świata, lecz podąża za jego bywalcami i przyjmuje ich perspektywę, by koncentrować się na jednostkowych potrzebach. Kiedy $\mathrm{w}$ Informatorze Jeffrey Wigand zostaje zwolniony przez korporację tytoniową, przemianie ulegają też odwiedzane przez bohatera miejsca. Utrata bezpieczeństwa ekonomicznego skutkuje rozpadem mentalnym. Chemika zaczynają prześladować jego własne, zdeformowane odbicia, dostrzegane między innymi w lustrzanych drzwiach windy; domowa przestrzeń ulega optycznemu pomniejszeniu, a otoczenie pola golfowego, zamiast uspokajać, odstrasza bohatera barwą trującej zieleni.

Jeśli uznać, zgodnie z myślą Erwina Panofsky’ego, że styl jest sposobem manipulowania niestylizowaną rzeczywistością fizyczną[29], to wybory Michaela Manna służą przede wszystkim wydobyciu specyfiki i sporządzeniu wizualnego komentarza do świata późnego kapitalizmu: odrażającego, zrujnowanego moralnie i osaczającego bohaterów, którzy bezskutecznie poszukują bezpieczeństwa. Przyjęta strategia może zaskakiwać, ponieważ Mann faworyzuje przestrzenie zaanektowane przez rzeczników wielkiego kapitału. Stała obecność bieli i szarości, schludnych kadrów, ekskluzywnych apartamentów i awangardowych klubów nocnych, przywiązanie do obłych przedmiotów i gładkich powierzchni, fetyszyzacja technologii i drogich gadżetów, celebracja męskiego profesjonalizmu i etosu pracowników wysokiego szczebla, kreują profil swoistej „estetyki korporacyjnej” o wyraźnym zabarwieniu marketingowym. Choć twórca deklaruje nieufność wobec powierzchownego piękna i opiera się etykietom modernisty[30], to - zdaniem Matta Zollera Seitza - pozostaje przywiązany do estetyki reklam telewizyjnych, ukierunkowanych zwłaszcza na sprzedaż wartości: determinacji, skupienia i zaangażowania[31]. Świat Manna jest wypełniony modnymi ubraniami, drogimi pojazdami i szklanymi fortecami, a mamieni ideologią sukcesu protagoniści bezkrytycznie podążają za wizualnymi oznakami bogactwa.

Sięgając po metody analizy ideologiczno-klasowej, Choon-Piew Pow zwraca uwagę, że przyjemność czerpana z kontaktu z finezyjnie zaaranżowanymi przestrzeniami oraz skłonność do ochrony ich piękna znamionuje starania elit. W interesie decydentów leży sprzyjanie wysublimowanym gustom, będące w gruncie rzeczy narzędziem marginalizowania klasy niższej i sposobem potwierdzania własnej wyjątkowości[32]. Estetyzacja pracowników wysokiego szczebla jest w twórczości Manna wyłącznie pozorną pochwałą klasy posiadającej. Reżyser podkreśla wykluczający profil przestrzeni korporacyjnych i złowieszczość marketingowej fasady. Minimalizm i „zmysł estetyczny”,

[28] A. Piskorz, op.cit., s. 186.

[29] Zob. E. Panofsky, Style and medium in motion pictures, [w:] The Visual Turn: Classical Film Theory and Art History, red. A.D. Vacche, New Brunswick 2003 , s. 83.
[30] Zob. S. Foundas, op.cit.

[31] Zob. M.Z. Seitz, op.cit.

[32] C.P. Pow, Neoliberalism and the aestheticization of new middle-class landscapes, „Antipode” 2009, $\mathrm{nr}$ 41, s. 373. 
początkowo uwodzicielskie, $\mathrm{z}$ czasem prowadzą do rozpadu tożsamościowego. W Czerwonym smoku monumentalne budowle powodują niepokój, a sterylne korytarze pogłębiają paranoję Grahama. W Goraczce mieszkańcy wyrafinowanych, lecz zimnych [33] i nieprzyjaznych apartamentów tęsknią za intymnością kameralnych przestrzeni. Z kolei stalowe garnitury bohaterów Informatora i Zakładnika stanowią symboliczne bariery oddzielające portretowanych indywidualistów od reszty świata - także tego, którego częścią chcieliby się stać.

Twórczość reżysera w większym stopniu niż jednolitością stylistyczną odznacza się obecnością zbieżnych motywów narracyjnych i ikonograficznych. Opowieści o destrukcyjnym oddziaływaniu współczesności każdorazowo wyrastają $\mathrm{z}$ fascynacji życiem w wielkim mieście. Tuż przed rozpoczęciem pracy bohater filmu Zakładnik obserwuje wieloetniczny, hałaśliwy tłum. Przytłacza go nadmiar bodźców: odgłosy pracy mechaników z pobliskiego warsztatu, rozmowy telefoniczne, obrazy z kamer monitoringu, relacje sportowe i wszechobecne reklamy. W stechnicyzowanych amerykańskich metropoliach bohaterom towarzyszy nieznośna kakofonia klaksonów, krzykliwych rozmów i dźwięków pracy. Dopiero zamknięcie drzwi pojazdu wycisza otoczenie. Spokój jest jednak pozorny. Bohater doznaje wolności od zgiełku, jednak wpędza się w pułapkę indywidualizmu. Wraz z pojawieniem się Vincenta, płatnego mordercy, pełna izolacja okaże się toksyczna i niebezpieczna.

Poszczególne motywy narracyjne, z pesymizmem wypływającym $\mathrm{z}$ wielkomiejskiego pejzażu i subiektywizacją spojrzenia na czele, uzmysławiają przywiązanie reżysera do wzorców kina noir i neo-noir. Zgodnie z tradycją nurtu przestępcy wciąż spotykają się w ciemnych alejkach, gdzie padają na nich wąskie strumienie światła (Złodziej), a „stróże prawa” nocą odkrywają ofiary seryjnych morderców (Gorącz$k a$ ). Abstrahując od prawideł fabularnych i estetycznych, Mann poddaje rewizji poetykę kina czarnego. Agresywny światłocień i niski klucz oświetleniowy nie skrywają już najpoważniejszych niebezpieczeństw miejskiego życia. Ambiwalencja wypływa z przemieszania kategorii zagrożeń. To, co współcześnie okazuje się naprawdę groźne, jest skąpane w oślepiającej bieli[34]. Miliarder z Goraczki, zarządy korporacji z Informatora i działający poza prawem przedsiębiorcy z Miami Vice (2006) funkcjonują w centrach amerykańskich miast i zajmują apartamenty zlokalizowane na szczytach drapaczy chmur. Zło doby późnego kapitalizmu nie musi ukrywać się przed aparatami państwa. Korporacyjni decydenci są widoczni w przestrzeni publicznej - w przeciwieństwie

[33] Zob. T. Ambrose, LA Story. The making of Michael Mann's „Heat”, „Scraps from the Loft” 2018, $<$ https://scrapsfromtheloft.com/2018/03/29/michael-mann-the-making-of-heat/>, dostęp: 20.03.2020.
[34] W Goraczce przestępca Neil McCauley wymyka się policyjnej obławie. Zmierza na lotnisko, gdzie czeka na niego samolot - przepustka do nowego życia. Kiedy bohater wjeżdża do rozświetlonego tunelu i doświadcza rażącej jasności ostrej bieli, ponownie ogarnia go potrzeba wypełnienia zobowiązań. 
do pomniejszych przestępców, których fizyczny trud i ciężka harówka są niemal przez autora romantyzowane.

Szerokoekranowy format filmów Michaela Manna odsłania ruchliwość, bujność i energię amerykańskich metropolii. W neonowo-stroboskopowych spektaklach miejskiego życia bohaterowie poszukują możliwości zrealizowania swoich marzeń. Choć twórca sławi nocne pejzaże, to protagoniści rzadko są pogrążeni w całkowitym mroku. Nawet jeśli kryją się w cieniu, to i tak podlegają inwigilacji kamer termowizyjnych, fundujących wysokokontrastowy obraz (Gorączka). Znacznie częściej miasta mienią się glonową poświatą: ciemność jest rozpraszana przez blask ulicznych latarni i reflektorów samochodowych, a w połyskliwych karoseriach pojazdów odbijają się światła sygnalizacyjne i krzykliwe barwy przydrożnych telebimów. Obserwowane z dystansu samochody pozostawiają czerwone smugi - przypominające krwiobieg ponowoczesnego świata, w którym nigdy nie zamiera przepływ kapitału. Tym samym reżyser przypisuje metropolitalnym przestrzeniom cechy żywego organizmu: inwazyjnego, rozrastającego się i ruchliwego drapieżnika. Akcję w filmach Manna ustanawiają ujęcia $\mathrm{z}$ lotu ptaka, portretujące rozległe zabudowania $\mathrm{z}$ niedostępnej bohaterom perspektywy, ale też detale, będące udziałem codziennego doświadczenia mieszkańców. Reżyser przygląda się nocnemu życiu miast $\mathrm{z}$ bliska i daleka, portretuje je w zwolnionym i przyspieszonym tempie, analizuje pod kątem prywatnym i publicznym, bo, jak sam wspomina, „noc musi być trójwymiarowa”[35].

Upodobanie do przeskoków między planami totalnymi i zbliżeniami ma silną motywację psychologiczną. W Goraczce, w osławionej sekwencji napadu na bank i strzelaniny w śródmieściu Los Angeles, szerokie kadry afirmują spokój i metodyczność grup profesjonalistów. Kiedy wraz z konfrontacją narasta chaos, postępującą dezorientację percepcyjną odzwierciedlają detale i subiektywne spojrzenia bohaterów. Z pietyzmem zaaranżowane starcie odsłania przy okazji predylekcję twórcy do autentyzmu[36]. Scena, choć widowiskowa, nie przypomina ani naznaczonych heroizmem pojedynków z kina reaganowskiego, ani finezyjnego baletu przemocy, przeniesionego na grunt amerykańskiej kinematografii z tradycji Dalekiego Wschodu. W naznaczonej realizmem scenie obławy Mann fetyszyzuje minimalizm ruchów, słów i gestów. Żonglerka planami przydaje strzelaninie sznytu paradokumentalnego, a uwaga kamery koncentruje się na atrybutach męskich profesjonalistów: broni, samochodach i innych "narzędziach pracy”, przypisując im tym samym moc sprawczą.

Faktyczny charakter odwiedzanych miejsc objawia się wraz z doznaniem dotkliwej niepewności. Wizualnym komentarzem życia wewnętrznego bohaterów jest aura. $\mathrm{O}$ autorskiej sygnaturze reżysera stanowi umiejętność przekuwania nastroju i atmosfery świata w obrazy i dźwięki. Ostatecznie, jak twierdzi Mann, styl jest przejawem odwie- 
dzanych miejsc i esencją środowisk, w których funkcjonują protagoniści. Nie jest zatem wtórny wobec rzeczywistości pozafilmowej, lecz z rzeczywistości wypływa[37].

\section{Zabójcza zieleń dolara}

Zgodnie z przypisywanym Thomasowi Sowellowi cytatem kapitalizm zna tylko barwę zieloną. Wszystkie inne, odnoszone na przykład do ras, płci, seksualności lub pochodzenia etnicznego, są kolorami drugorzędnymi lub „służalczymi” względem tego, który wyróżnia amerykańską walutę. Protagonista serialu Wydział kryminalny (2002), policjant prowadzący dochodzenie pod przykryciem, w trakcie rozmowy z przestępcą wygłasza przekonujące credo: „Teraz możesz zobaczyć, jaki mam kolor. Zielony. Jak pieniądze. PIENIĄDZE”. W filmach Manna miłość do bogactwa bywa zaraźliwa i wszechogarniająca. W Miami Vice, tuż po sensualnej scenie kąpieli, przepojonej nostalgiczną barwą sepii, Sonny niespodziewanie ukróca namiętny nastrój i inicjuje biznesowe negocjacje z kochanką. W Alim małżonka przestrzega tytułowego bohatera przed bokserskim promotorem: „Mówi jak czarny, żyje jak biały, a myśli tylko o zielonych", definiując tym samym pragnienie większości Mannowskich protagonistów. Niezależnie od emocjonalnego zaangażowania i wyznawanych poglądów niemal wszyscy ulegają przemożnemu wpływowi dolara.

Kiedy w Gorązce okazuje się, że jeden z członków grupy przestępczej nie może wziąć udziału w napadzie na bank, lider rekrutuje do zadania dawnego znajomego z więzienia. Choć recydywista zapewniał wcześniej swoją partnerkę, że zniesie upokorzenia tymczasowej pracy, finansowy trop wydaje się zbyt wyraźny i kuszący. Nie mogąc znieść myśli o zatrudnieniu w przydrożnym barze, Donald ulega zrozumiałej fantazji. Kiedy przystępuje do ponownej realizacji amerykańskiego snu, wokół niego pojawia się zielonkawy poblask. Zgoda na uczestnictwo w feralnym napadzie będzie miała dla niego fatalne konsekwencje. Bohaterowie twórczości Manna nie ustają w wysiłkach na rzecz odnalezienia źródła dobrobytu. W Czerwonym smoku Hannibal Lecktor zwraca się do głównego bohatera: „Chcesz zwietrzyć trop, obwąchaj siebie". Zgodnie $\mathrm{z}$ amerykańskim mitem tropienie jest praktyką charakteryzującą poczynania zwycięzców, co wyraźnie poświadcza Martin Scorsese w filmie Kolor pieniędzy (1986). W scenie zapowiadającej pojedynki turniejowe doświadczony bilardzista zadaje towarzyszom pytanie: „Czujecie ten zapach?” Choć odpowiedź jest oczywista, naiwny uczeń dopytuje: „Dymu?”, czym wzbudza konsternację. Partnerka nastolatka znudzonym głosem podpowiada mu: „Pieniędzy”. W realizacjach Manna protagoniści podejmują próbę zwęszenia bogactwa. W Goraczce, tuż po sforsowaniu włazu sejfu wypełnionego milionami dolarów, słychać wyraźnie, że włamywacz Shiherlis bierze bardzo głęboki wdech. Upo-

[37] Zob. M. Sragow, Mann among men, „Salon” 1999, <http://www.salon.com:8o/bc/1999/02/o2bc.html>, dostęp: 13.03.2020. 
jenie się zapachem jest jedynie tymczasowe, bo zieleniąca się waluta, zamiast aromatu sukcesu, roztacza wokół siebie morowe powietrze.

Podobna aura towarzyszy Maksowi, który, wbrew zasadom korporacji taksówkarskiej, zgadza się pełnić funkcję prywatnego szofera Vincenta. Pojazd mężczyzny stanowił zamkniętą i odizolowaną od świata przestrzeń, jednak, wraz z zawarciem umowy z płatnym mordercą, zaczął odznaczać się zieloną poświatą. Ten szczególny typ jasności, często opromieniający niebezpieczne miejsca, do których trafiają bohaterowie, jest, zdaniem Davide’a Panagii, podstawowym wydarzeniem świetlnym w twórczości Manna. Obok światła, które pada na obiekty, uświadamiając tym samym ich obecność, istnieje jeszcze nieumotywowany diegetycznie blask pochodzący z wnętrza filmowych realiów[38]. Mann mówi o nim: „Niech światło wypełnienia stanie się kluczowym światłem" [39]. Iluminujące bohaterów żarzenie okazuje się wizualnym komentarzem sytuacji, oznaką potrzeb i pragnień jednostek.

Ed Howard i Jason Bellamy zwracają uwagę na pozorną banalność gatunkową i fabularną filmów Manna. W tych realizacjach nieskomplikowane historie ujęte są w proste, znajome formuły (najczęściej kryminał, dreszczowiec i dramat społeczny). Zdaniem krytyków wyjątkowość dzieł reżysera jest definiowana przez nastrój i atmosferę, osiąganą dzięki zainteresowaniu szczegółami świata[40]. Choć styl Manna nie jest spójny, to w aurze poszczególnych produkcji wyraża się ciągłość autorskich poszukiwań. Mimo przeskoków z poetyki noir do teledyskowych narracji typu MTV, z niespiesznej konwencji biopików do dynamicznego kina akcji, filmy Manna spaja nadrzędny kod. Jest nim rozpad tożsamościowy człowieka osaczonego przez nieprzyjazną rzeczywistość.

Choć F.X. Feeney podkreśla, że stosowana przez Manna paleta barw nie ma stałego znaczenia symbolicznego, to nawet intuicyjne kombinacje (zieleni i szaleństwa, bieli i opresji, szarości i profesjonalizmu, błękitu i bezpieczeństwa oraz czerni i śmierci) kumulują ładunek emocjonalny zakorzeniony w fabule[41]. Zdaniem Vincenta M. Gaine’a nieuchronność losów bohaterów jest często portretowana zielonymi składnikami mise-en-scène. W zielonych przestrzeniach czai się niebezpieczeństwo, a bohaterów noszących zielone ubrania spotyka ponury los. W głównej jednak mierze ta „zatruta” barwa, złowieszcza i skorumpowana, przestrzega przed gorączkową realizacją marzenia o awansie społecznym [42]. Z początku, w domu tytułowego Złodzieja, są obecne nieliczne, szmaragdowe elementy wystroju. Wraz z rozwojem fabuły kolor amerykańskiego dolara coraz wyraźniej otacza bohatera. Do ostatecznej konfrontacji dojdzie przecież na zieleniącym się traw-

[38] Zob. J. Holben, op.cit.

[39] Zob. ibidem.

[40] Zob. J. Bellamy, E. Howard, The Conversations. Michael Mann, „Slant” 2009, <https://www.slantmagazine.com/film/the-conversations-michael-mann/>, dostęp: 10.03.2020.
[41] Zob. F.X. Feeney, op.cit., s. 55.

[42] Zob. V.M. Gaine, Existentialism and Social Engagement in the Films of Michael Mann, Hampshire 2011, s. 63. 
niku przed domem lidera organizacji przestępczej, której struktura wspiera się na modelu korporacyjnym[43]. W tych okolicznościach pęknięcie tożsamości Franka uzmysławia bankructwo amerykańskiego marzenia.

Protagoniści konsekwentnie dążą do osiągnięcia założonego poziomu dobrobytu, ale atmosfera świata późnego kapitalizmu okazuje się zbyt przytłaczająca. Chroniący się przed wpływem korporacyjnych decydentów bohaterowie umykają w miejsca zapewniające im przynajmniej chwilowe wytchnienie. Ukojenie gwarantuje im błękit oceanu, faktycznego lub wyobrażonego w snach i fantazjach. Blask jego wód wyzwala w protagonistach tęsknotę za niegdysiejszą harmonią. Sceny wieńczące filmy Michaela Manna ukazują zwykle chwile emocjonalnego wyciszenia. Wówczas bohaterowie nie są niesieni prądem miejskiego życia, lecz metaforycznie dryfują na spokojnych wodach. Dokonującą się transgresję uzmysławia zwłaszcza Gorączka. Vincent Hanna, policjant $\mathrm{z}$ wydziału kryminalnego, obsesyjnie tropiący przestępców i wystawiający się na pełne spektrum zmysłowych doznań, w jednej z rozmów z żoną wyznaje swój światopogląd: „Muszę trwać w napięciu. Utrzymuje mnie w formie, na krawędzi. Tam jest moje miejsce”. Podczas wygłaszania życiowej idei wskazuje na serce, jak gdyby adrenalina zasilała jego organizm. Gwałtowne pstrykanie palcami uzmysławia rytm tej dynamicznej egzystencji. Z czasem zmysły bohatera okazują się tak nadwyrężone, że Hanna przyjmuje autodestrukcyjną orientację i faktycznie zaczyna balansować na krawędzi. Finałowa konfrontacja, w której detektyw staje naprzeciw swojego przestępczego sobowtóra, paradoksalnie stanowi moment wytłumienia emocji i ustabilizowania pulsu. Rozstrzygnięcie konfliktu jest jednocześnie formą symbolicznego pojednania postaci. W trakcie tego kameralnego spotkania drapieżna do tej pory rzeczywistość na krótką chwilę przybiera kojącą tonację.

W podobnych okolicznościach sytuują się bohaterowie Złodzieja, Czerwonego smoka i Informatora. Nie mogąc dłużej trwać w zmysłowym przeciążeniu, szukają dla siebie azylu - miejsc anulujących imperatyw ciągłego ruchu, wykańczającej pracy i bogacenia się. W tych wyjątkowych momentach protagoniści doświadczają emocjonalnego rozprężenia. Kiedy stają nad brzegiem oceanu, kamera koncentruje się wyłącznie na nich. Życie wokół zamiera, dźwięki są wytłumione, a barwy stonowane. Kontemplacja pejzażu i emocjonalne skupienie służą wydobyciu szczególnego nastroju chwili. Majestatyczny widok wyzwala w bohaterach potrzebę intymnego kontaktu $\mathrm{z}$ drugim człowiekiem. Szepty, szczere rozmowy, cielesna bliskość, czułe spojrzenia i uściski dłoni wyrażają tęsknotę za „innym” życiem. Pod wpływem tych doznań protagoniści nierzadko podejmują próbę uwolnienia się od wpływów wielkiego kapitału i ucieczki przed obowiązkami. Nie ma jednak możliwości powrotu do dawnej, spokojnej egzystencji. Sieci ekonomicznych zależności są nadto rozległe i złożone. Poczucie bezwładu

[43] Zob. ibidem. 
w jałowym świecie późnego kapitalizmu definiuje profil Mannowskiej melancholii[44]. Niebieska barwa wielkiej wody przywraca komfort psychiczny wyłącznie tymczasowo, a bohaterowie przekonują się, że błękit jest kolorem zbyt bliskim „ciemności”[45]. Naruszając przyjęte zobowiązania, ściągają na siebie gniew wszechpotężnych mocodawców. W konsekwencji, zamiast odnaleźć ukojenie nad brzegiem oceanu, osuwają się w jego ponurą, czarną otchłań.

Althusser L., Ideologie i aparaty ideologiczne państwa, przeł. A. Staroń, „Recykling idei" 2006, <http://recyklingidei.pl/althusser-ideologie-aparaty-ideologiczne-panstwa>, dostęp: 16.03.2020

Ambrose T., LA Story. The making of Michael Mann's "Heat”, "Scraps from the Loft” 2018, <https://scrapsfromtheloft.com/2018/03/29/michael-mann-the-making-of-heat/>, dostęp: 20.03.2020

Barker J.M., Out of sync, out of sight: Synaesthesia and film spectacle, „Paragraph" 2008, nr 31, DOI: 10.1353/prg.0.0011

Bauman Z., Życie na przemiat, przeł. T. Kunz, Kraków 2004

Bellamy J., Howard E., The conversations. Michael Mann, „Slant” 2009, <https:// www.slantmagazine.com/film/the-conversations-michael-mann/>, dostęp: 10.03.2020

Brody R., The Stylish, Empty Realism of Michael Mann, „The New Yorker” 2016, 5. February, <https://www.newyorker.com/culture/richard-brody/the-stylish-empty-realism-of-michael-mann>, dostęp: 16.03.2020

Davis M., Planeta slumsów, przeł. K. Bielińska, Warszawa 2009

Feeney F.X., Michael Mann, Los Angeles 2006

Foundas S., A Mann's man's world, „LA Weekly” 2006, 26 lipca, <https://www. laweekly.com/news/a-manns-mans-world-2144449>, dostęp: 10.08.2019

Gaine V.M., Existentialism and Social Engagement in the Films of Michael Mann, Hampshire 2011

Haithman D., This Man's Got a 'Vice' He Can Live With: 'Style is a Dirty Word,'Producer Michael Mann Says, „Los Angeles Times” 1987, 17. November, <https://www.latimes.com/archives/la-xpm-1987-11-17-ca-22158-story.html>, dostęp: 10.03.2020

Helman A., Refleksje teoretyczne. Kilka uwag o stylu w filmie, „Kino” 1978, nr 4

Holben J., Hell on Wheels: Collateral, „American Cinematographer” 2019, 18. October, <https://ascmag.com/articles/hell-on-wheels-collateral>, dostęp: 10.03.2020

Jameson F., Postmodernizm, czyli logika kulturowa późnego kapitalizmu, przeł. M. Płaza, Kraków 2011

Knight R.W., Michael Mann's Miami Vice, „Reverse Shot” 2008, 26. April, <http:// www.reverseshot.org/symposiums/entry/70/michael_mann>, dostęp: 20.02.2020

Koepnick L., Aura widziana na nowo. Benjamin i wspótczesna kultura wizualna, przeł. K. Kosińska, „Kwartalnik Filmowy” 2008, nr 64

Mann M., Paint it Black, rozm. przepr. M. Olsen, [w:] Michael Mann. Cinema and Television. Interviews, 1980-2012, red. S. Sanders, R.B. Palmer, Edinburgh 2014

McGowan T., Realne spojrzenie. Teoria filmu po Lacanie, przeł. K. Mikurda, Warszawa 2008

[44] Por. S. Rybin, op.cit., s. 130.

[45] Zob. M. Rzepińska, Historia koloru w dziejach malarstwa europejskiego, Kraków 1983, s. 443. 
Mościcki P., Odrodzenie aury z ducha fotogenii, „Teksty Drugie” 2016, nr 2, DOI: 10.18318/td.2016.2.6

Panofsky E., Style and medium in motion pictures, [w:] The Visual Turn: Classical Film Theory and Art History, red. A.D. Vacche, New Brunswick 2003

Piskorz A., Michael Mann - antropolog doświadczenia, [w:] Mistrzowie kina amerykańskiego. Współczesność, red. Ł.A. Plesnar, R. Syska, Kraków 2010

Pow C.P., Neoliberalism and the aestheticization of new middle-class landscapes, "Antipode" 2009, nr 41, DOI: 10.1111/j.1467-8330.2009.00677.x

Riffaterre M., Kryteria analizy stylu, „Pamiętnik Literacki” 1972, nr LXIII z. 3

Rybin S., Michael Mann. Crime Auteur, Lanham 2013

Rzepińska M., Historia koloru w dziejach malarstwa europejskiego, Kraków 1983

Seitz M.Z., Zen Pulp, „Moving Image Source” 2009, <http://www.movingimagesource.us/articles/zen-pulp-pt-1-20090701>, dostęp: 10.03.2020

Sharrett C., Michael Mann. Elegies on the post-industrial landscape, [w:] Fifty Contemporary Filmmakers, red. Y. Tasker, Routledge, London, New York 2002

Sragow M., Mann among men, „Salon” 1999, <http://www.salon.com:80/ bc/1999/02/02bc.html>, dostęp: 13.03.2020

Srnicek N., Navigating Neoliberalism. Political Aesthetics in an Age of Crisis, <https:// vimeo.com/52434614>, dostęp: 24.02.2020. 